Original Research Article

\title{
Primary dysmenorrhea: evaluation and treatment pattern among female medical students
}

\author{
Sapna Gupta, Sharminder Kaur*, Shamiya Sadiq, Vijay Khajuria
}

Department of Pharmacology, Govt. Medical College, Jammu, $\mathrm{J} \& \mathrm{~K}$, India

Received: 29 August 2018

Revised: 13 September 2018

Accepted: 17 September 2018

*Correspondence to:

Dr. Sharminder Kaur,

Email: joharsharminder@ gmail.com

Copyright: (C) the author(s), publisher and licensee Medip Academy. This is an openaccess article distributed under the terms of the Creative Commons Attribution NonCommercial License, which permits unrestricted noncommercial use, distribution, and reproduction in any medium, provided the original work is properly cited.

\begin{abstract}
Background: Dysmenorrhea is a very common condition in females in fertile age group and its affective and somatic features often limit female mobility which results in loss of work hours. The aim of the study was to evaluate prevalence, severity, drug usage and loss of work days among young female medical students. Methods: The current questionnaire based study was done in Department of pharmacology, GMC Jammu over a period of 3 months. Female students aged between 17-24 years who consented for participation were included. The demographic profile and detailed history of dysmenorrhea was recorded.

Results: Out of 342 participants, 218 females $(63.7 \%)$ had history of dysmenorrhea. Most of the dysmenorrhic females had menarche between 13-14 yrs of age (73.3\%) and menstrual cycle of $21-34$ days $(82.5 \%)$, duration of bleeding less than 6 days $(91.6 \%)$ and had a positive family history of dysmenorrhea $(58.7 \%)$. Majority of females had mild to moderate features of dysmenorrhea (93.4\%). Most common medication was Mefenemic acid alone and in combination $(90.5 \%)$. Most of the females took self-medication $(69.8 \%)$ and only $30.2 \%$ took medicines on advice of doctor. $71.5 \%$ students missed their classes due to symptoms of dysmennorhea.

Conclusions: Dysmenorrhea is quite prevalent among college going medical students. Most of them had positive family history. Mefenemic acid and its combination was frequently used to treat symptoms. On an average 1-2days were lost due to dysmenorrhea.
\end{abstract}

Keywords: Dysmenorrhea, Female medical students, Mefenemic acid, Menarche, Self medication

\section{INTRODUCTION}

Dysmenorrhea is defined as pain during menstruation. Most common symptoms are pelvic or lower abdominal pain, backache, diarrhea or nausea. These symptoms usually start at the time of menstruation and subside within three days. ${ }^{1}$

The prevalence rates of dysmenorrhea differ by age, however more than $50 \%$ of women in all age groups experience dysmenorrhea. The prevalence rate worldwide is between $50.9 \%$ to $87.4 \% .^{2}$
Dysmenorrhea is either primary or secondary. Primary dysmenorrhea usually occurs in adolescents shortly after menarche without underlying macroscopic pelvic pathology. Overproduction of uterine prostaglandins contributes towards its pathogenesis. Secondary dysmenorrhea is associated with conditions like endometriosis or pelvic inflammatory disease. Risk factors for dysmenorrhea include early age at menarche, longer menstrual periods, heavy menstrual flow and family history of dysmenorrhea. ${ }^{1,3,4}$

Intervention to management of dysmenorrhea is either pharmacological or non-pharmacological. Non- 
pharmacological methods include: applying hot compresses, adopting a knee to chest position or drinking hot beverages including warm water or milk, coffee or soup to ease cramps. Common pharmacological treatments advocated include NSAID's and hormones. ${ }^{2}$

Since, dysmenorrhea is associated with loss of work days therefore its management is of utmost importance especially in students, as they will be experiencing difficulties in completing their study curriculum. Therefore, keeping in mind it was thought of interest to evaluate the pattern of dysmenorrhea among medical students to have deeper insight into the issue with emphasis on to find the prevalence of dysmenorrhea and usage of various drugs among medical college students.

Aim of the study was to evaluate prevalence, severity and drug usage in primary dysmenorrhea among young female medical college students.

\section{METHODS}

A questionnaire based study was conducted in Govt. Medical College Jammu from June 2018 to August 2018 with prior approval of Institutional ethics committee.

\section{Inclusion criteria}

All female medical students aged between 17 to 24 years who volunteered were included in the study.

\section{Exclusion criteria}

- All female students of more than 25 years of age, those on concomitant medication including antipsychotics, antidepressants, sedative-hypnotics, antispasmodics or corticosteroids.

Following data was collected:

Demographic characteristics, menstrual history including age at menarche, severity and duration of dysmenorrhea, number of days missed at class due to dysmenorrhea and details of medication whether prescribed by physician or self medicated were evaluated.

\section{Statistical analysis}

Analysis was carried out and data was expressed in $\mathrm{n}(\%)$ in table form.

\section{RESULTS}

Total 342 college going females were evaluated. Out of which 218 were found to be suffering from dysmenorrhea $(63.7 \%)$ while $124(36.25 \%)$ did not give any history of dysmenorrhea. Most of the dysmenorrhic females were in the age group of $19-21$ years $(77.9 \%)$. Most of females suffering from dysmenorrhea had menarche at 13-14 years. $79.8 \%$ of the dysmenorrhic females had regular menstrual cycles while rest $(21.1 \%)$ had irregular cycles. $82.5 \%$ of dysmenorrhic females had menstrual cycle of 21 34 days, while $91.7 \%$ had menstrual bleeding for a period of around six days. $58.7 \%$ of them had positive family history of dysmenorrhea in mothers or sisters (Table 1).

Table 1: Demographic and menstruation characteristics.

\begin{tabular}{|c|c|c|c|}
\hline \multirow[t]{2}{*}{ Variables } & \multicolumn{2}{|c|}{ Dysmenorrhea } & \multirow[t]{2}{*}{ Total } \\
\hline & Yes n $(\%)$ & No n $(\%)$ & \\
\hline \multicolumn{4}{|l|}{ Age (years) } \\
\hline $16-18$ & $16(7.3)$ & 0 & 16 \\
\hline $19-21$ & $170(77.9)$ & $108(87)$ & 278 \\
\hline $22-24$ & $32(14.6)$ & $16(12.9)$ & 48 \\
\hline Total & 218 & 124 & 342 \\
\hline \multicolumn{4}{|c|}{ Age at menarche } \\
\hline$<12$ years & $32(14.6)$ & $24(19.3)$ & 56 \\
\hline 13-14 years & $160(73.3)$ & $88(70.9)$ & 248 \\
\hline$\geq 15$ years & $26(11.9)$ & $12(9.6)$ & 38 \\
\hline \multicolumn{4}{|l|}{ Regularity } \\
\hline Regular & $174(79.8)$ & $108(87)$ & 282 \\
\hline Irregular & $44(20.1)$ & $16(12.9)$ & 60 \\
\hline \multicolumn{4}{|c|}{ Menstrual cycle } \\
\hline$\leq 20$ Days & $08(3.6)$ & $08(6.4)$ & 16 \\
\hline 21-34 Days & $180(82.5)$ & $104(83.8)$ & 284 \\
\hline$>35$ Days & $30(13.7)$ & $12(9.6)$ & 42 \\
\hline \multicolumn{4}{|c|}{ Duration of bleeding days } \\
\hline$\leq 6$ Days & $200(91.7)$ & $104(83.8)$ & 304 \\
\hline$\geq 7$ Days & $18(8.2)$ & $20(16.1)$ & 38 \\
\hline \multicolumn{4}{|c|}{ Family history } \\
\hline Yes & $128(58.7)$ & $24(19.3)$ & 152 \\
\hline No & $90(41.2)$ & $100(80.6)$ & 190 \\
\hline
\end{tabular}

Majority (52.2\%) of dysmenorrhic females had duration of dysmenorrhea of less than six months while $47.7 \%$ had duration of more than six months. $47.2 \%$ had moderate severity of dysmenorrhea followed by $46.2 \%$ of the mild severity and only $7.3 \%$ dysmenorrhic subjects had severe features of dysmenorrhea. $69.7 \%$ of the dysmenorrhic females did not seek medical advice for the amelioration of symptoms of dysmenorrhea. $78(35.77 \%)$ of subjects missed their classes due to the physical symptoms of dysmenorrhea (Table 2).

Most preferred drug for the management of pain during dysmenorrhea was Mefenemic acid alone and in combination. $20.3 \%$ used mefenemic acid alone while $70.2 \%$ subjects consumed Mefenemic acid in combination with others. $4.6 \%$ subjects used Pitofenone+Diclofenac+ Fenpiverinium combination. Hormones were also taken by $4.6 \%$ subjects falling in severe category of dysmenorrhea (Table 3).

Out of 218 only $128 \quad(58.7 \%)$ subjects used pharmacological drugs while $90(41.2 \%)$ used nonpharmacological measures like hot compresses, adopting a knee to chest position or drinking hot beverages (Table 4). 
Table 2: Factors associated with dysmenorrhea.

\begin{tabular}{|ll|}
\hline Parameters & No. of patients \\
\hline Duration of dysmenorrhea & \\
\hline$\leq 6$ months & $114(52.2)$ \\
\hline$\geq 6$ months & $104(47.7)$ \\
\hline Severity of dysmenorrhea \\
\hline Mild \\
\hline Moderate & $100(46.2)$ \\
\hline Severe & $102(47.2)$ \\
\hline Medical advice & $16(7.3)$ \\
\hline Yes & \\
\hline No & $66(30.2 \%)$ \\
\hline No. of days missed at class & $152(69.7 \%)$ \\
\hline A Day prior to periods & 06 \\
\hline $1^{\text {st }}$ day & 58 \\
\hline $2^{\text {nd }}$ day & 10 \\
\hline $3^{\text {rd }}$ day & 04 \\
\hline
\end{tabular}

Table 3: Drugs used for pain management.

\begin{tabular}{|lc|}
\hline Drugs used & n(\%) \\
\hline Mefenemic acid & $26(20.3)$ \\
\hline Mefenemic acid + Drotaverine & $22(17.1)$ \\
\hline Mefenemic acid + Dicyclomine & $68(53.1)$ \\
\hline $\begin{array}{l}\text { Pitofenone+Diclofenac+ Fenpiverinium } \\
\text { bromide }\end{array}$ & $06(4.6)$ \\
\hline Hormones & $06(4.6)$ \\
\hline Total & 128 \\
\hline
\end{tabular}

Table 4: Menstrual pain management behavior.

\begin{tabular}{|lll|}
\hline $\begin{array}{l}\text { Pharmacological } \\
\text { measures } \mathbf{n}(\%)\end{array}$ & $\begin{array}{l}\text { Non-pharmacological } \\
\text { measures } \mathbf{n}(\%)\end{array}$ & Total \\
\hline $128(58.7 \%)$ & $90(41.2 \%)$ & 218 \\
\hline
\end{tabular}

Out of total 128 dysmenorrhic females, only 43(33.5\%) took medications under the advice of the physician while most of the dysmenorrhic subjects $85(66.40 \%)$ practiced self-medication (Figure 1).

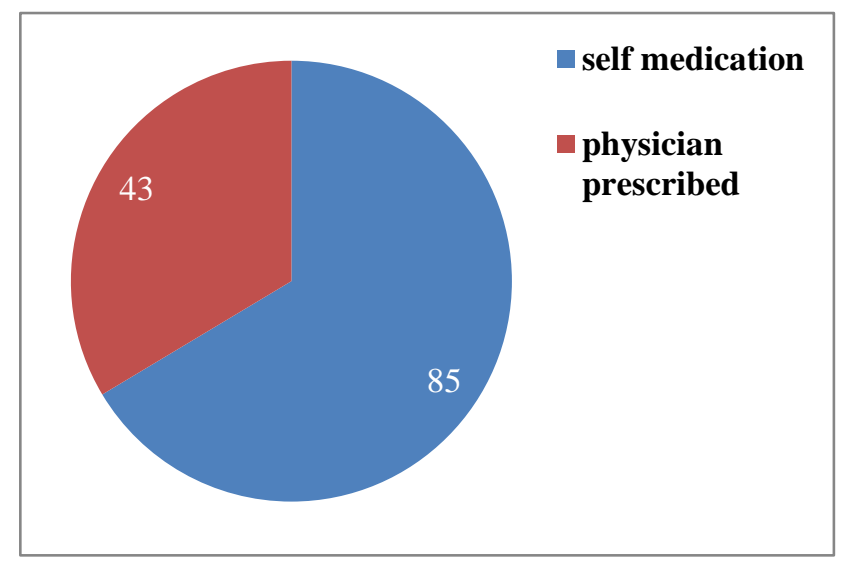

Figure 1: Self medication in percentages.

\section{DISCUSSION}

Current central Government's main thrust is to improve the economy of the country and there is a effort to tap the potential of young population and their skill development. Therefore, all out efforts are to increase the working hours and to improve the attendance in the educational institutions and offices. Female population receives the maximum attention in this regard. Govt. has come up with many policies like "Beti Padao" to generate more employment for females. ${ }^{5}$

Females form the backbone of the society and particularly doctors hold enormous responsibilities. However, dysmenorrhea which is a common problem that ails the females cyclically during every month and the associated pain in the lower abdomen and pelvis, affective and somatic features often limit their output and result in their absence from educational institutions.

Therefore, the main objective of the current study was to have a deeper insight into the issue of dysmenorrhea and have a detailed account of the days lost, medical remedies with hope that the outcome of this study will have impact on the society.

During the current study the prevalence rate of dysmenorrhea amongst female medical students was $63.7 \%$ which is lower than previously reported prevalence rate $(71.8 \%)$ by Yesuf TA et al,. ${ }^{6}$ Reason could be that since dysmenorrhea was diagnosed based solely on a girl's perception of pain, which is difficult to quantify and could be related to non-menstrual events.

In this study, $64.5 \%$ females had menarche below 13-14 years and bleeding days of 6 or less. The results are in concurrence with the studies done by Kumbhar SK et al, and Sherpa SZ et al,., ${ }^{7,8}$

One of the interesting finding was that $78.9 \%$ of females had positive family history of dysmenorrhea though it is difficult to explain direct relationship, probably genetic basis plays a significant role. Naheed et al, and Sherpa SZ et al 2017 have also illustrated the role of family history in causation of dysmenorrhea. ${ }^{8,9}$

Most of the females had mild (47.2\%) to moderate (46.2\%) severity of dysmenorrhea - pain being the usual feature similar to the results observed by Omidvar $\mathrm{S}$ et al,. The factors responsible for pain in dysmenorrhea may be multifactorial but the most predominant is excess of Prostaglandin F2 $\alpha$. It has been observed that PgF $2 \alpha$ levels are twice higher in dysmenorrhea females than nondysmenorrhea females during menstruation. ${ }^{10}$

Since the prostaglandins are potent pro-inflammatory agents, the role of NSAIDs in combating dysmennorhea gets highlighted. In the present study, Mefenemic acid alone and in combination with dicyclomine were the most 
commonly used drugs. Similar to results observed by Marjoribanks J et al, and Sugumar R et al,. ${ }^{11,12}$

Even though 58\% of dysmenorrhic girls used pharmacological methods for treatment, only $30.2 \%$ of these sought medical advices. This points towards the conclusion that $69.8 \%$ resorted to self-medication. This is similar to observations made by Ortiz MI et al, who reported a self medication rate of $60.9 \% .{ }^{13}$ This high rate of self medication can be easily explained as the study population was medical students and had easy access to the treatment modalities of dysmenorrhea. Nonpharmacological methods were used by $41.2 \%$ participants which is similar to the results made by Sugumar $\mathrm{R}$ et al,. ${ }^{12}$

On an average $71.5 \%$ students missed their classes due to psychosomatic features coupled with pain of dysmenorrhea and this is in consistent with the observations of Kumar SK et al 2016. ${ }^{14}$ Most of the students missed college on first day followed by second day and some in premenstrual period. Such reports are there but none has reported in a classified way. In this study $30.2 \%$ of girls with dysmenorrhea sought medical advice. This percentage was higher than that seen in other studies by Lakshmi SA et al 2011 and Kumar SK et al,.. 14,15 Reason could be the inclusion of medical students in the study group who have easy accessibility to health care professionals.

As the study was done in the young medical students and they are well versed with the treatment modalities, therefore the findings will be different if compared with general population as they do not have frequent access to the treatment. Therefore, the days lost may be higher in those females. Thus, population in general needs to be educated regarding the disorder and should be encouraged to have treatment during these days which will eventually result in more working hours and contribute towards the growth of nation.

\section{CONCLUSION}

Dysmenorrhea is a quite prevalent condition in the young female college students and most of them had positive family history and opted for pharmacological intervention. Mefenemic acid was most commonly used drug and on an average 1-2 days was lost due to dysmenorrhea.

Funding: No funding sources

Conflict of interest: None declared

Ethical approval: The study was approved by the Institutional Ethics Committee

\section{REFERENCES}

1. Helwa HAA, Mitaeb AA, Hamshri SA Sweilch WM. Prevalence of dysmenorrhea and predictors of its pain intensity among Palestinian female University Students. BMC Womens Health. 2018;18:18.
2. Chiu MH, Hsieh HF, Yang YH, Chen HM, Hsu SC, Wang HH. Influencing factors of dysmenorrhea among hospital nurses; a questionnaire survey in Taiwan. BMJ OPEN.2017;7(12).

3. Dawood MY. Dysmenorrhea and Prostaglandins In: Gynecologic endocrinology, Boston. Springer. 1987:405-421.

4. Proctor M, Farquhar C. Diagnosis and management of dysmenorrhea. BMJ. 2006;332(7550):1134-8.

5. Saini V, Sangwan S. Awareness on gender empowerment and Beti Bachao Beti Padhao through intervention. IJRHAL. 2018;6(1):227-34.

6. Yesuf TA, Eshete NA, Sisay EA. Dysmenorrhea among University Health Science Students, Northern Ethopia: Impact and Associated Factors. IJRMED. 2018;2018.

7. Kumbhar SK, Reddy M, Sujana B, Roja RK, Divya BK, Balakrishna C. Prevalence of Dysmenorrhea among Adolescent Girls (14-15 years) of Kadapa District and its impact on quality of life: A Cross Sectional Study. Nati J Commu Med. 2011;2(2):2658.

8. Sherpa SZ, Devi R, Dangol A, Limbu A, Chettri I, Gurung J, et al. Knowledge Regarding Dysmenorrhea and its Health Seeking Behavior in Colleges of Sikkim. Asian J Nur Edu Resea. 2017;7(4):477-81.

9. Parveen N, Majeed R, Rajar UDM. Familial predisposition of dysmenorrhea among the medical students. Pak J Med Sci. 2009;25(5):857-60.

10. Omidvar S, Bakouei F, Amiri FN, Begum K. Primary Dysmenorrhea and Menstrual Symptoms in Indian Female Students: Prevalence, Impact and Management. Glob J Health Sci. 2016;8(8):53632.

11. Marjoribanks J, Proctor M, Farquhar C, Sangkomkamhang US, Derks RS. Nonsteroidal antiinflammatory drugs for primary dysmenorrhea. Cochrane Database System Rev. 2003.

12. Sugumar R, Krishnarah V, Channaveera GS, Mruthyunjaya S. Comparison of the pattern, efficacy and tolerability of self-medicated drugs in primary dysmenorrhea: A questionnaire based survey. Ind $\mathbf{J}$ Pharmacol. 2013;45(2):180-3.

13. Ortiz MI, Rangel-flores E. Carrillo-Alaroon LC, Veras-Godoy HA. Prevalence and Impact of Primary dysmenorrhea among Mexican high school students. Int J Gynaecol Obstet. 2009;107(3):240-3.

14. Kumar KS, Konjengbam S, Devi HS. Dysmenorrhea among Higher Secondary School girls of Imphal West district, Manipur: A cross-sectional study. J Med Soc. 2016;30(1):38-43.

15. Lakshmi SA, Priya M, Saraswathi I, Saravanan A, Ramachandran C. Prevalence of premenstrual syndrome and dysmenorrhea among female medical students and its association with college absenteeism. Intl J Biol Med Res. 2011;2:1011-6.

Cite this article as: Gupta S, Kaur S, Sadiq S,

Khajuria V. Primary dysmenorrhea: evaluation and treatment pattern among female medical students. Int J Basic Clin Pharmacol 2018;7:1873-6. 